\title{
Despegue frustrado: costo de vida y estándares de vida en el Perú durante el siglo XIX
}

\author{
Leticia Arroyo Abad ${ }^{* *}$
}

\begin{abstract}
RESUMEN
Basado en diversas fuentes primarias, este artículo presenta estimaciones del costo de vida y de los estándares de vida para Lima, Perú durante el siglo XIX. Durante ese siglo, dicho país experimentó profundas fluctuaciones en la actividad económica debido a las guerras de independencia, la guerra del Pacífico y al auge monoexportador. Estos factores alimentaron un importante proceso inflacionario durante la era del guano que tuvo efectos adversos en los estándares de vida de las clases populares. Es de notar que los estándares de vida llegaron a su punto máximo a mediados de la década de 1850 mientras que el PBI per cápita lo hizo dos décadas más tarde. Estos resultados sugieren que la bonanza del guano no logró mejorar el bienestar económico de las clases populares de manera sustentable. A pesar de alcanzar niveles similares a Inglaterra, estos beneficios se evaporaron hacia el fin de siglo.
\end{abstract}

Palabras clave: niveles de vida, costo de vida, crecimiento económico.

Clasificación JEL: N36

Failure to Launch: Cost of Living and Living Standards in Peru during the 19th Century

\begin{abstract}
Based on a variety of archival sources, this paper presents estimations for cost of living and living standards for Lima, Peru during the 19th century. During this century Peru experienced deep swings in economic activity marked by the independence wars, the War of the Pacific, and a commodity boom. These new series show that a sizable inflationary period during the guano age had dampening effects on the living standards of the popular class. While living standards peaked by mid 1850s, GDP per capita did not do so until two decades later. These results suggest that the guano bonanza failed to lift working-class living standards above subsistence levels. Even though living standards climbed steadily, almost reaching those of England, all these gains were lost by the end of the century.
\end{abstract}

Keywords: levels of living, costs of living, economic growth.

JEL Code: N36

* Quisiera dar las gracias a los cuatro árbitros anónimos y al editor por sus comentarios y sugerencias. Agradezco el apoyo financiero proporcionado por la National Science Foundation y la American Philosophical Society. Este artículo es una traducción realizada por Jan David Gelles, del original publicado en Revista de Historia Económica - Journal of Iberian and Latin American Economic History, 32(01), 47-76. Marzo 2014.

** Middlebury College, Departament of Economics, Carr Hall 209, Middlebury, VT 057533, USA. larroyoabad@middlebury.edu 


\section{INTRODUCCIÓN}

La importancia del Perú en el imperio español es innegable. Como fuente clave de plata, mercurio y mano de obra indígena, estas tierras se convirtieron en un pilar del dominio colonial espańol. La explotación de la plata tuvo un papel importante en la conformación de la estructura económica y social de esta colonia. Además, España estableció un sistema de comercio colonial muy restringido y el Perú tenía uno de los pocos puertos autorizados para comerciar con la madre patria. Dado este rol prominente en el imperio, las elites conservadoras, profundamente arraigadas en esta estructura colonial, se convirtieron en un fuerte bastión contrario a la independencia de España. No sorprende entonces que la independencia fuese una empresa costosa y difícil en dicho territorio considerando que la élite estaba alineada con la Corona para proteger sus intereses económicos.

A pesar de la ruptura de los lazos coloniales a principios del siglo XIX, la plata se mantuvo como la piedra angular económica del Perú (después de una caída durante las guerras de independencia) siguiendo un nuevo giro nacionalista. Un par de décadas más tarde, Perú se convirtió en el principal proveedor mundial del famoso fertilizante de estiércol de ave: el guano. El impacto de la explotación del guano en la economía peruana fue impresionante. Se convirtió en el principal producto de exportación, alcanzó el 74\% del total de las exportaciones en 1853, y se convirtió también en la principal fuente de ingresos públicos. El PBI per cápita pasó de unos \$ 400 dólares Geary-Khamis de 1990 en vísperas de la independencia a \$1124 en 1876. Esta notable experiencia de crecimiento económico puso al Perú solo 15\% por debajo del PBI per cápita de la Argentina durante el mismo periodo. El agotamiento del modelo guanero y las vicisitudes de la guerra del Pacífico evaporaron el crecimiento alcanzado. Casi dos décadas después de la guerra, la economía peruana recuperó un poco de terreno a partir del nuevo siglo con un PBI per cápita de $\$ 674^{1}$.

Durante el siglo XIX, Perú quedó atrapado entre dos estrategias basadas en productos básicos: la plata colonial y el guano poscolonial. Mientras que el auge del guano ha atraído mucha atención en la literatura, el estudio del siglo XIX en su conjunto ha generado menos aportes. Además, aunque se han explorado muchas facetas de la bonanza del guano, sus efectos sobre el bienestar y el costo de vida han recibido poca atención. En general, la literatura está de acuerdo en que el auge del guano no se tradujo en desarrollo sostenible para el país (Hunt, 1973; Bonilla, 1974; Tantaleán Arbulú, 1983; y Gootenberg, 1993). En cambio, el Perú no aprovechó esta oportunidad y el auge rápidamente se desmoronó.

\footnotetext{
1 Los datos del PBI per cápita se han tomado de Seminario de Marzi (2011). ......(VERIFICAR ubicación referencia en texto)....
} 
En este trabajo contribuyo a la literatura estudiando la evolución del costo de vida y los estándares de vida durante todo el siglo $\mathrm{XIX}^{2}$. Usando fuentes primarias a partir de una serie de archivos peruanos, se construyen series de costo de vida y bienestar para Lima desde 1820 hasta 1900. Para evaluar la evolución del costo de vida, se ha continuado el trabajo publicado por Gootenberg (1990) para el resto del siglo XIX usando fuentes similares ${ }^{3}$. Se estima el costo de la canasta de subsistencia del hogar usando una metodología comparable a la aplicada en el trabajo pionero de Allen (2001). Además, se ha calculado un índice de precios con la estructura de la canasta básica desarrollada por Gootenberg (1990). Utilizando los salarios de la mano de obra no calificada a partir de fuentes públicas, es posible calcular el coeficiente de bienestar definido como el número de canastas básicas que un hogar obrero podía alcanzar en un año. Ese indicador permite entonces la comparación con otras ciudades y países para el mismo periodo.

A partir de estas nuevas series, se descubre que Lima sufrió un marcado cambio en el costo y en el nivel de vida durante el siglo XIX. Hubo un periodo inicial de deflación tras las guerras de independencia, seguido por inflación durante el auge del guano. Los precios se duplicaron entre la década de 1840 y principios de la de 1870 , mientras que se mantuvieron estables después de la deflación experimentada durante la guerra del Pacífico. Esta fluctuación dramática de los precios tuvo efectos perjudiciales sobre el nivel de vida de las clases populares. Los salarios nominales no se actualizaron al ritmo del aumento de los precios, lo que resultó en una caída general en el nivel de vida antes de la conclusión del auge del guano. Este resultado sugiere que las ganancias de este episodio de crecimiento no fueron generalizadas. De hecho, el PBI per cápita alcanzó su máximo en 1876, dos décadas después de que el coeficiente de bienestar lo alcanzase. Esta divergencia indica que los ingresos provenientes del auge del guano en la última etapa probablemente beneficiaron al segmento superior de la población. Estos resultados están de acuerdo con la evidencia antropométrica presentada por Twrdek y Manzel (2010). En este estudio los autores documentan que de 1820 a 1880 la altura media de la clase baja no mejoró.

El estudio del costo de vida y los estándares de vida en este trabajo comienza con el trasfondo histórico del Perú durante el siglo XIX, seguido por una discusión de las fuentes, la metodología y la presentación de la serie de costo de vida usando la canasta básica y otra serie similar a la de Gootenberg (1990). Dichas series se comparan con el índice estimado por esta autora. Utilizando la canasta de subsistencia y los datos de salarios nominales, se presentan las series sobre el nivel de vida medido por el coeficiente de bienestar. Luego, se analizan los niveles de vida del Perú en perspectiva histórica y comparada y finalmente se ofrecen conclusiones.

\footnotetext{
2 Lamentablemente, todos los datos corresponden a la ciudad de Lima. Dado el tamaño y la heterogeneidad del mercado peruano, no es posible determinar el costo de vida y el nivel de vida de otras regiones.

3 Su índice de precios y series de precios abarcaban el periodo 1800 a 1873.
} 


\section{PERÚ EN EL SIGLO XIX: EL CONTEXTO ECONÓMICO}

La historia económica del Perú durante el siglo XIX está marcada por notables choques políticos y económicos. De las guerras al auge del guano, este país transitó por un camino sinuoso después del dominio colonial. Para facilitar la discusión de las tendencias históricas en Perú durante el siglo XIX, se eligió una simple periodización. La primera etapa, desde la década de 1820 hasta la de 1840, se caracteriza por las guerras de independencia y los legados y cambios del dominio colonial. La segunda etapa, desde la década de 1850 hasta la de 1870, es un periodo marcado por la modernización y el auge de las materias primas. Finalmente, la tercera etapa abarca el resto del siglo XIX, una fase caracterizada por la guerra del Pacífico, la crisis, y sus consecuencias ${ }^{4}$.

\subsection{Periodo I: Legados COlONiALES, GUERRAS y CAMBio (DÉCADAS De 1820 a 1840)}

La independencia de España llegó tarde al Perú en comparación con el resto de América del Sur. Perú también fue diferente ya que las fuerzas revolucionarias externas jugaron un papel importante en el proceso. Como resultado, algunos sectores influyentes siguieron siendo simpatizantes del poder colonial dado sus intereses creados en la estructura productiva colonial (Quiroz, 1993). Inmediatamente después de la independencia, el Estado continuó utilizando las instituciones coloniales ya existentes. Por ejemplo, las principales fuentes de ingresos fiscales, el tributo a la población indígena y los ingresos de la minería de plata, representaron dos tercios de los ingresos totales (Dancuart, 1905). A pesar de esta inercia, las necesidades de fondos del nuevo gobierno llevaron a un aumento en los aranceles 5 . No obstante las importantes medidas proteccionistas iniciales, el gobierno disminuyó las tasas arancelarias y los ingresos aduaneros se volvieron cada vez más importantes, alcanzando el 52\% del total de los ingresos públicos en 1831 (Tantaleán Arbulú, 1983).

En términos de producción, la plata continuó siendo la principal fuente de exportación, representando el $50 \%$ de las exportaciones totales hasta ser desplazada por el guano ${ }^{6}$. La producción general se desplomó en la década de 1820 como resultado de la inesta-

\footnotetext{
4 Soy consciente de que las periodizaciones pueden encubrir otros cambios y continuidades relevantes en los procesos históricos; sin embargo, pueden ayudar a iluminar tendencias claves. Tantaleán Arbulú (2001) sugiere una periodización similar: (1) el periodo del caudillismo militarista (1821-1840), la era del guano (1840-1879); (2) el periodo de la guerra del Pacífico; y (3) la reconstrucción nacional y la industrialización temprana.

5 Los aranceles no fueron estables durante este periodo. Por ejemplo, la tasa arancelaria para la indumentaria empezaba en un 49\% en 1821, subió al 80\% en 1826 y cayó al 30\% en 1836 (Tantaleán Arbulú, 2001). 6 Las cifras exactas para las exportaciones de plata son escasas, ya que a menudo se combinan con la moneda de plata. Para un estudio más completo sobre las exportaciones, véase Hunt (1973). Para la década de 1840, Hunt (1973) proporciona la cantidad de plata exportada y Deustua (1986) publica los precios de exportación. Las exportaciones totales provienen de Contreras (2004). Deustua (2000) estudia la minería en el Perú del siglo XIX.
} 
ble situación económica y política, pero recuperó el dinamismo unos años más tarde. En la década de 1840, la producción recuperó los niveles de principios del siglo XIX (Gootenberg, 1990; Quiroz, 1993). Las guerras de independencia interrumpieron gravemente el funcionamiento de los sectores del azúcar y de la importación. La producción de azúcar disminuyó sustancialmente a medida que los esclavos fueron reclutados por primera vez para los ejércitos y a la vez que el conflicto dificultó el transporte.

En general, la inestabilidad de los tiempos de la Independencia tuvo un impacto negativo en el crecimiento del PBI. Durante el primer cuarto del siglo XIX, el PBI cayó $30 \%$. La mayor caída ocurrió durante la década de 1820, cuando la tasa de crecimiento anualizada fue del $-2,3 \%$ (véase la Tabla 1). Recién en 1840 el Perú alcanzó el nivel del PBI similar al de antes de la guerra. Esta grave disminución de la actividad económica fue acompañada por una significativa deflación; el nivel de precios solo se estabilizó a finales de 1840 .

\subsection{Periodo II: Modernización y AUge (DÉCADAS de 1850 A 1870)}

La modernización de la economía peruana siguió al auge del guano. Tantaleán Arbulú (2001, p. 400) afirma que este fertilizante causó una «verdadera revolución [y] que creó las condiciones objetivas para el crecimiento y la modernización». La dependencia de las exportaciones de guano alcanzó su pico en 1853, con el $74 \%$ de las exportaciones totales, disminuyendo al 56\% y al $40 \%$ durante las dos décadas siguientes (Hunt, 2011). Este auge tuvo profundos efectos en la economía peruana, desde un fuerte aumento de los ingresos fiscales hasta la expansión del mercado interno ${ }^{7}$. La actividad económica creció durante las primeras décadas, llegando a un crecimiento anual del PBI del 4,7\% en la década de 1850. El PBI per cápita alcanzó su máximo en 1876 con \$ 1123 dólares Geary-Khamis de 1990, 90\% más elevado que en 1850. Los sectores minero, manufacturero y minorista aumentaron su participación general en el PBI, mientras que la agricultura fue el perdedor claro (basado en Seminario de Marzi, 2011).

\footnotetext{
7 La literatura sobre los efectos de la explotación de un nuevo recurso natural es abundante. En el caso del guano, algunos autores afirman que la economía se podía caracterizar como un enclave, ya que esta industria no desarrolló ningún vínculo con otros sectores (véase Bonilla, 1974), por ejemplo). Otros cuestionan esta visión de los efectos significativos del desarrollo de la industria del guano en la economía (véase Hunt, 1984, 1996). Una cuidadosa consideración de todas estas caracterizaciones está más allá del alcance de este artículo.
} 
Tabla 1. Crecimiento y exportaciones, décadas de 1820 a 1840

\begin{tabular}{|c|c|c|c|}
\hline & \multicolumn{3}{|c|}{ Década } \\
\hline & 1820 & 1830 & 1840 \\
\hline Actividad económica & & & \\
\hline $\begin{array}{l}\text { Crecimiento PBI (\%) } \\
\text { Tasa de crecimiento anualizada }\end{array}$ & $-2,3$ & 3,1 & 3,9 \\
\hline $\begin{array}{l}\text { Agricultura }(\%) \\
\text { Como } \% \text { del PBI }\end{array}$ & 64,4 & 63,1 & 57,4 \\
\hline $\begin{array}{l}\text { Dinamismo de las exportaciones } \\
\text { Crecimiento } \\
\quad \text { Promedio, quantum }(1900=100)\end{array}$ & n.d. & 15,9 & 30,9 \\
\hline
\end{tabular}

Fuentes: PBI y agricultura: Seminario de Marzi (2011), crecimiento de las exportaciones: Hunt (1973).

Desde una perspectiva fiscal, las exportaciones de guano ayudaron a las cuentas públicas, triplicando los fondos disponibles en la década de 1850, desplazando a otras formas de tributación, ya que contribuyeron hasta el $83 \%$ de los ingresos totales entre 1857 y 1869, y promediaron más del 55\% durante este periodo (véase la Tabla 2) . $^{8}$ El flujo repentino de recursos financió la expansión del gobierno, de 1848 a 1878, más del $50 \%$ de los ingresos provenientes del guano financiaron el crecimiento de la burocracia civil y militar (Hunt, 1984) .

La política fiscal expansionista tuvo efectos sobre el tamaño del mercado doméstico. Una nueva generación de empleados públicos amplió el mercado interno (Contreras, 2004). Asimismo, el $20 \%$ de los fondos del guano se destinaron a la construcción de ferrocarriles. Este proyecto pretendía disminuir los costos de transporte y dotar al país de una infraestructura de transporte. Desafortunadamente, el proyecto estuvo plagado de dificultades y no se completó hasta después de la guerra del Pacífico.

\subsection{Periodo III: GUeRra y ReCUPERACión (DÉCADAS DE 1880 A 1890)}

La guerra con Chile, conocida como la guerra del Pacífico, junto con el agotamiento del modelo guanero marcaron una nueva etapa en la historia peruana.

8 Otros desarrollos fiscales incluyen un incremento significativo de la deuda pública; véase por ejemplo a Gootenberg (1989) y a Vizcarra (2009).

9 Según Hunt (1984), el resto de los fondos del guano se destinaron a ferrocarriles (20\%), transferencias a peruanos $(11,5 \%)$, transferencias a extranjeros $(8 \%)$ y reducción de la carga fiscal $(7 \%)$. La categoría de burocracia civil también incluye las obras públicas no militares. 
Tabla 2. Crecimiento, exportaciones y cuentas fiscales, décadas de 1820 a 1870

\begin{tabular}{|c|c|c|c|}
\hline & \multicolumn{3}{|c|}{ Década } \\
\hline & 1850 & 1860 & 1870 \\
\hline Actividad económica & & & \\
\hline $\begin{array}{l}\text { Crecimiento del PBI (\%) } \\
\text { (Tasa de crecimiento anualizada) }\end{array}$ & 4,7 & 2,1 & $-1,6$ \\
\hline $\begin{array}{l}\text { Agricultura }(\%) \\
\text { (Como \% del PBI) }\end{array}$ & 46,6 & 43,8 & 41,7 \\
\hline Dinamismo de las exportaciones & & & \\
\hline $\begin{array}{l}\text { Crecimiento } \\
\quad(\text { Promedio, quantum }(1900=100))\end{array}$ & 64,0 & 83,5 & 121,2 \\
\hline Cuentas fiscales & & & \\
\hline $\begin{array}{l}\text { Ingresos del guano }(\%) \\
\text { (Participación en el ingreso total, por década) }\end{array}$ & 60,6 & 59,9 & 55,4 \\
\hline $\begin{array}{l}\text { Crecimiento de los ingresos }(\%) \\
\text { (Crecimiento por década en términos reales) }\end{array}$ & 227,3 & 127,8 & 142,3 \\
\hline
\end{tabular}

Fuentes: PBI y agricultura: Seminario de Marzi (2011), crecimiento de las exportaciones: Hunt (1973); cuentas fiscales: Tantaleán Arbulú (2001).

A principios de la década de 1870 las reservas de guano estaban gravemente agotadas. Asimismo, el desarrollo de un fertilizante artificial estaba erosionando rápidamente el predominio que el guano había adquirido. Ante las terribles circunstancias fiscales, el gobierno recurrió al sector de los nitratos para resolver sus problemas ${ }^{10}$. En 1873 , impuso un impuesto a la exportación de los nitratos, pero los mayores productores no cumplieron con los nuevos requerimientos. El gobierno respondió expropiando 161 compañías de nitratos. El conflicto armado surgió cuando el gobierno boliviano aumentó los impuestos a la exportación de nitratos, un movimiento que violaba un tratado entre Bolivia y Chile. Dada la importancia de los nitratos en la economía peruana y la alianza secreta entre Perú y Bolivia, el Perú fue incitado a participar en la guerra.

Los resultados fueron devastadores para la economía peruana. La actividad económica se desplomó a medida que el PBI total disminuyó más del 30\% entre 1879 y 1883 (véase la Tabla 3) ${ }^{11}$. Perú perdió también la provincia Tarapacá, rica en nitratos, mientras que Bolivia perdió el acceso al océano Pacífico. Desde el punto de vista fiscal, el Estado estaba en quiebra. Los ingresos fiscales disminuyeron de 35 millones de soles en 1879 a alrededor de un millón en 1883 (Klarén, 2005). El sector exportador dejó de ser el generador de ingresos, ya que las exportaciones de guano y nitratos desaparecieron. En 1887, las exportaciones representaron solo el 23\% del nivel previo a la guerra (Yepes, 1992).

\footnotetext{
${ }^{10}$ Para una descripción completa de la crisis fiscal peruana en este periodo en perspectiva histórica, véase Contreras (2012).

${ }^{11}$ La caída del PBI per cápita según las cifras de Maddison (2007) fue de 26\% para el mismo periodo
} 
La recuperación solo se puso en marcha después de la resolución del problema de la deuda externa. El crecimiento del PBI alcanzó el 1,7\% anual durante la década de 1890 a pesar de la turbulencia causada por la crisis de Barings. Para la segunda mitad de esta década, las exportaciones recuperaron el dinamismo impulsado por la depreciación cambiaria y la inversión (Thorp y Bertram, 1978). En particular, el sector manufacturero se estaba expandiendo rápidamente, con una tasa de crecimiento anual de $18 \%$ en 1896.

Tabla 3. Crecimiento y exportaciones, décadas de 1880 a 1890

\begin{tabular}{l|c|c}
\hline \multirow{2}{*}{} & \multicolumn{2}{|c}{ Décadas } \\
\cline { 2 - 3 } & 1880 & 1890 \\
\hline $\begin{array}{l}\text { Actividad económica } \\
\text { Crecimiento del PBI (\%) } \\
\quad(\text { Tasa de crecimiento anualizada) }\end{array}$ & $-1,8$ & 3,9 \\
$\quad \begin{array}{c}\text { Agricultura (\%) } \\
\quad(\text { Como \% del PBI) }\end{array}$ & 64,0 & 63,7 \\
$\begin{array}{l}\text { Dinamismo de las exportaciones } \\
\quad \text { Crecimiento } \\
\quad(\text { Promedio, quantum }(1900=100))\end{array}$ & 42,6 & 65,0 \\
\hline
\end{tabular}

Fuentes: PBI y agricultura: Seminario de Marzi (2011); crecimiento de las exportaciones: Hunt (1973).

\section{SALARIO MÍNIMO VITAL Y BIENESTAR}

La investigación sobre precios y salarios en América Latina siguió los pasos de historiadores como Hamilton. Romano (1963) y Florescano (1968) fueron pioneros en el estudio de los precios latinoamericanos, seguidos por Johnson y Tandeter (1990); sin embargo, el alcance y la cobertura variaron sustancialmente entre países. Si bien muchos de estos estudios corresponden a la época colonial, en décadas recientes han surgido estudios para el siglo XIX. Por ejemplo, Williamson (1999) calculó los salarios reales de varios países de la región con cobertura parcial del siglo XIX. Desde el punto de vista nacional, la cobertura es escasa para la mayor parte de la región. En el caso de México, Gómez-Galvarriato y Musacchio (2000) crearon un índice de costo de vida para fines del siglo XIX. Para Venezuela, Arroyo Abad (2013) analizó el costo de vida y los estándares de vida para el siglo XIX. Relativamente hablando, hay más estudios disponibles para el cono sur. Cuesta $(2007,2012)$ estudió los precios del siglo XVIII y la evolución de los salarios reales en Buenos Aires para el periodo 1850-1913. Bértola (2000) y Braun et al. (2000) presentan un índice de costo de vida para Uruguay y Chile respectivamente. Para el Perú, Macera (1992) reunió la colección más impresionante de precios al por menor para diferentes localidades urbanas y rurales durante la época colonial. Gootenberg (1990) examinó el costo de vida en Lima para la mayor parte del siglo XIX. 
Para estimar el costo de vida y los niveles de vida es necesario recolectar los precios al consumidor y los salarios. La mayoría de los estudios citados anteriormente proporcionan datos y/o análisis sobre los precios y sus tendencias. Sin embargo, los datos sobre salarios son más escasos en general, y más aún en el caso del siglo XIX. La desarticulación del sistema colonial trajo consigo consecuencias tangibles para la estructura política, social y económica de las posesiones españolas, incluyendo la recolección de datos y el mantenimiento de registros. Como resultado, la compilación de estos datos es difícil y lenta, especialmente cuando se compara con la investigación disponible para la época colonial. A pesar del desafío, observamos algunos avances en algunos países. En el caso de Perú, el estudio pionero de Hunt (1980) fue complementado por Zegarra (2011) sobre salarios y pobreza para principios del siglo XX.

El estudio de la evolución histórica del costo de vida y los estándares de vida en todo el mundo ha sido muy fructífera últimamente. Una nueva generación de estudios ha examinado diferentes áreas del mundo durante largos periodos de tiempo, inspirados por el trabajo seminal para Europa de Allen (2001). Como resultado de este trabajo, nuevos estudios utilizaron canastas de consumo similares para comparar los niveles de vida en todo el mundo. Utilizando metodologías comparables, Özmucur y Pamuk (2002) trabajaron sobre el Imperio Otomano, la India fue abordada por Allen (2007), seguido por Allen et al. (2011) para países seleccionados de Asia. Más recientemente, Cvrcek (2013) examinó el Imperio Habsburgo durante el siglo XIX. Para América Latina, Arroyo Abad et al. (2012) estudiaron las tendencias a largo plazo para una muestra de ciudades durante la época colonial. Sin embargo, hay una brecha en la literatura para el siglo XIX con la excepción de Venezuela. Arroyo Abad (2013) ha calculado tanto el costo de vida como el nivel de vida para el siglo XIX.

Utilizando los datos ya disponibles para el Perú del siglo XIX y complementándolos con mi propio trabajo de archivo, este trabajo utiliza la metodología diseñada por Allen (2001) y ampliada por Arroyo Abad et al. (2012). Como se detalla a continuación, la metodología también incluye otras canastas de consumo disponibles de otras fuentes.

\subsection{Precios e Índices de Precios}

Los precios corresponden a transacciones minoristas en la ciudad de Lima. Gootenberg (1990) publicó precios al por menor para más de veinte productos de 1825 a 1873. Siguiendo sus huellas, se ha completado la serie recolectando datos del resto del siglo XIX de fuentes similares ${ }^{12}$. Los datos de los precios fueron tomados del Archivo del Arzobispo de Lima. Los registros corresponden a iglesias y monasterios tales como

\footnotetext{
${ }^{12}$ La cobertura varía según el bien y el año. Excluyendo los años de la guerra del Pacífico, la cobertura varió del $50 \%$ al $85 \%$ del total de ańos estudiados.
} 
Trinitarias y Santa Clara ${ }^{13}$. En comparación con los datos de precios modernos, estas fuentes presentan limitaciones. En primer lugar, estas instituciones eclesiásticas eran privadas y, como tal, seguían prácticas contables privadas. A menudo es imposible controlar la calidad y en ocasiones los precios obtenidos incluían un descuento «en nombre de Dios» ${ }^{14}$. A pesar de estas limitaciones, el consenso es que este tipo de fuente es la mejor disponible para los precios al por menor ya que cubren largos periodos de tiempo y los precios están basados en el mercado (Cuesta et al., 2011). La frecuencia se basa principalmente en transacciones mensuales. No todos los precios estaban disponibles para todos los años. Si la brecha era pequeña, la observación interviniente se interpoló. Los precios fueron cotizados en soles, pesos y reales. Utilizamos la conversión de 1 sol igual a 10 reales (Gootenberg, 1990) y los precios se convirtieron al sistema métrico. Desafortunadamente, no hay datos disponibles para el periodo 1875-1880. Siguiendo la metodología de Gootenberg, se estimó el precio de los textiles mediante los precios al por mayor de las telas de algodón de los Estados Unidos compilados por Hanes (2006) ${ }^{15}$.

Con los precios disponibles es posible trazar la evolución general de los precios en el tiempo; sin embargo, para estimar el costo de vida es necesario usar una canasta de consumo representativa. En este estudio se consideran dos tipos de canastas: una canasta de subsistencia y una canasta más completa. Para ambos casos, se utilizó un índice de ponderaciones fijas teniendo en cuenta las canastas de consumo que se describen a continuación. La primera canasta ofrece lo mínimo necesario para la subsistencia. También conocida en la literatura como la canasta de subsistencia, comprende unos pocos bienes bajo la categoría de "productos alimenticios» y otros bienes de consumo, tales como artículos diversos para prendas de vestir, calefacción e iluminación. La canasta presentada en la Tabla 1 es comparable con las utilizadas por Allen (2001) y Allen et al. (2011). La justificación detrás de la canasta de subsistencia es crear una canasta de consumo que refleje el "precio de la subsistencia», tal como lo introdujo Adam Smith en La Riqueza de las Naciones. Tal como se cita en Allen et al., Smith (1776) señaló que los salarios nominales pagados en Europa eran más altos que en China no solo como resultado de las diferencias en el costo de vida, en palabras de Smith, el "precio de la subsistencia», sino también porque la retribución a la mano de obra era mayor en Europa.

Para construir una canasta de ese tipo, se han consultado fuentes de la canasta original de Gootenberg (1990) y otras fuentes primarias para el siglo XIX ${ }^{16}$. En general, las clases populares tenían una dieta nutritiva, ya que la carne y el pan eran abundantes.

\footnotetext{
13 Archivo del Arzobispado de Lima, Trinitarias, 1883-1898 (Legajo IV, números 70, 111, 117-8, 126); Encarnación, 1873 (Legajo XXIX, número 47); Santa Clara, 1882-3 (Legajo XXXIV, números 14, 32, 111, 121); de la Trinidad, 1876-1900 (Archivo Intermedio, números 29, 32, 34, 72, 76, 77, 82, 86, 90, 95).

${ }_{14}$ Para una discusión sobre la confiabilidad de este tipo de fuentes, véase Romano (1992) y Johnson (1992).

${ }^{15}$ Contreras y Cueto (2004) también señalan que con la Independencia los obrajes sucumbieron a la competencia extranjera. Para las clases populares, Estados Unidos era el principal proveedor de textiles.

16 Véase Datos e informes (1870), Moreno (1897), Peloso (1985) y Ruiz Zevallos (2001).
} 
De hecho, la canasta de consumo no fue muy diferente (en términos del tipo de bienes consumidos) de la canasta de consumo de alimentos de las clases altas (Peloso, 1985). A partir de ellos, se ha estimado una canasta sencilla basada en los patrones de consumo de las clases populares en la ciudad de Lima. Se adoptó la metodología desarrollada por Allen et al. (2011) que considera el costo de vida en diferentes ciudades del mundo. Para Inglaterra, Allen (2001) creó una canasta que era demasiado onerosa para las regiones en vías de desarrollo. Como resultado, la canasta fue simplificada para incluir solo una selección de productos que proporciona las necesidades nutricionales mínimas de un adulto teniendo en cuenta las preferencias dietéticas de los habitantes de Lima, los limeños.

La Tabla 4 muestra la composición de esta canasta de subsistencia en comparación con canastas similares para otras ciudades en el mundo. Para Lima, la canasta considera una dieta de 1928 calorías donde la carne y el frijol son las principales fuentes de proteína. Esta ingesta calórica es similar a otras canastas de subsistencia en otras ciudades en la historia. Carnes, pan, arroz, frijoles y mantequilla son los únicos alimentos considera$\operatorname{dos}^{17}$. A partir de Moreno (1897) es posible estimar el promedio del consumo de carne basado en el número de bovinos sacrificados en la ciudad de Lima: 98,2 kg de consumo de carne por año ${ }^{18}$. Los demás bienes incluidos en la canasta incluyen artículos diversos como textiles para ropa, madera y velas para calefacción/iluminación y jabón. Todos estos elementos constituían un $95 \%$ del presupuesto total, reservando el resto para los costos de la vivienda y los artículos misceláneos. Como la canasta proporciona las cantidades anuales consumidas de cada producto, es posible calcular su costo monetario en moneda local. Para estimar el costo de vida de una familia de dos adultos y dos niños, la canasta individual de subsistencia se multiplica por tres ${ }^{19}$. Se supone que los dos menores consumen el equivalente de la canasta de un adulto. Esta metodología permite la comparación internacional del bienestar cuando se combina con los datos sobre salarios ${ }^{20}$.

\footnotetext{
${ }_{17}$ Para los frijoles, consideré los garbanzos y los frijoles regulares. Aunque tradicionalmente se asocia con la dieta típica peruana, las papas no aparecen en las canastas de consumo de Gootenberg (1990) y en todas las canastas, excepto una, presentadas en Datos e informes (1870). La manteca de cerdo fue sustituida por mantequilla debido a la disponibilidad; los registros del Archivo del Arzobispo de Lima solo ofrecían el precio de la mantequilla para fines del siglo XIX. En Datos e informes (1870) muchas de las canastas de consumo citan la mantequilla como la principal fuente de grasa.

18 Se dispone de otras estimaciones; sin embargo, se presenta la cifra más modesta. El porcentaje anual de consumo de carne de vacuno es de 167, 125 y 104 kg, para Gootenberg (1990), Ruiz Zevallos (2001) y Datos e informes (1870), respectivamente.

19 En los estudios sobre Bolivia y Perú en Johnson y Tandeter (1990) el tamańo del hogar era de dos adultos y dos niños.

20 Para periodos anteriores, sería posible comparar el costo de la canasta en gramos de plata. Dado el desorden monetario tras la Independencia, se ha optado por no incluir tal comparación
} 
Tabla 4. Canasta de subsistencia en perspectiva comparada

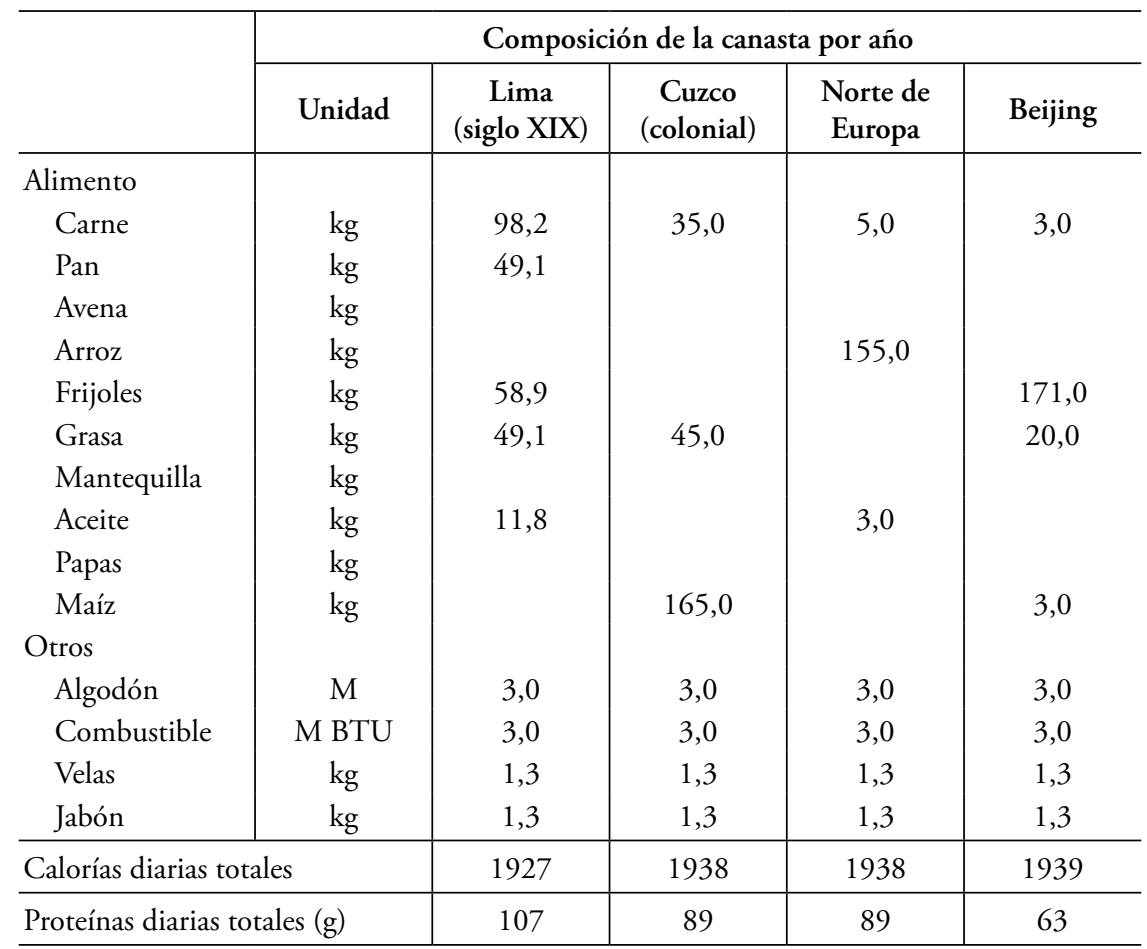

Notas: kg: kilogramos, M: metros, M BTU: millones de BTU.

Fuentes: Lima (siglo XIX): para las cantidades de alimentos, las estimaciones se basan en Datos e Informes (1870), pp. 111-119, Moreno (1897), pp. 171-174, Peloso (1985) pp. 52-58 y Ruiz Zevallos (2001), p. 41, el resto de los productos son de Allen (2001) y Arroyo Abad et al. (2012); Cuzco (colonial): Arroyo Abad et al. (2012), el norte de Europa y Pekín: Allen (2001) y Allen et al. (2011).

Todas las fuentes indican que los limeños tenían una fuerte preferencia por la carne. Esto es particularmente sorprendente cuando se compara con las canastas de Beijing y del norte de Europa. A excepción de las dietas de los esclavos hasta la década de 1850, todas las canastas citadas en Datos e informes (1870) contienen carne, en particular carne vacuna, como un componente importante de la dieta popular cotidiana. Además, Lima tenía un consumo de carne de vacuno por habitante más alto que Londres (Datos e informes 1870, pp. 130-131; Peloso 1985, p. 50). Según Macera (1974), Lima sobrepasó a Londres en términos de consumo de carne a mediados del siglo XIX. En una publicación periódica de la Sociedad Geográfica de Lima, el consumo de carne de vacuno ocupa un lugar prominente en comparación con otras grandes ciudades en 1897. 
Tabla 5. Canasta tradicional de consumo

\begin{tabular}{l|c|c}
\hline & Original (\%) & Ajustada (\%) \\
\hline Carne & 34,3 & 34,7 \\
Pan & 21,0 & 21,2 \\
Arroz & 8,0 & 8,1 \\
Frijoles & 8,0 & 8,1 \\
Azúcar & 5,1 & 5,2 \\
Grasa & 4,9 & 5,0 \\
Fideos & 1,8 & 1,8 \\
Combustible & 10,8 & 10,9 \\
Otros ítems & 6,1 & 5,0 \\
\hline Total & 100,0 & 100,0 \\
\hline
\end{tabular}

Fuente: basado en Gootenberg (1990, p. 14).

Según esta fuente, el consumo per cápita de Lima fue de 98,2 kg, seguido por los Estados Unidos y el Reino Unido con 54,5 y $47,7 \mathrm{~kg}$, respectivamente (Sociedad Geográfica de Lima, 1897). Al parecer, los observadores del siglo XIX, en cierta medida, criticaron el gusto limeño por la carne de vacuno.

Además de esta canasta básica, se ha calculado una canasta «tradicional» siguiendo las estimaciones de Gootenberg (1990) (ver la Tabla 5). A diferencia de la canasta anterior, esta establece una ponderación relativa de los componentes de consumo. Esta canasta incluye un conjunto más amplio de artículos de consumo, en particular en lo que respecta a los productos alimenticios. Se utilizó la dieta de artesanos para construir esta canasta y se modificó sobre la base del presupuesto de alimentos del hospital Santa Ana. Ambas fuentes son para el siglo XIX, los registros de Santa Ana corresponden a 1837, mientras que la dieta de artesanos es para el año 1869. Dado que la composición exacta de la categoría "otros» no es explícita, he recalculado los pesos reduciéndola a 5\% para artículos varios y vivienda. Como resultado, los diferentes componentes aumentan su participación en relación con el presupuesto original, como se muestra en la columna «Ajustada» de la Tabla 2. Al observar las ponderaciones, es claro que la mayor parte del presupuesto se dedicó a la carne y el pan con alrededor del 60\% del presupuesto total. Otros alimentos como arroz, frijoles, azúcar, manteca de cerdo y fideos representaban menos del $30 \%$ de la canasta de consumo.

En el Gráfico 1, se presentan los tres índices para su comparación: el índice original de Gootenberg, el índice de consumo de subsistencia y el índice original recalculado (el índice tradicional). No es sorprendente que los tres índices sigan tendencias similares: los coeficientes de correlación entre las dos series estimadas y el índice original de Gootenberg son altos, 0,9 y 0,94 , respectivamente. 
Gráfico 1. Costo de vida, índices de precios al consumidor

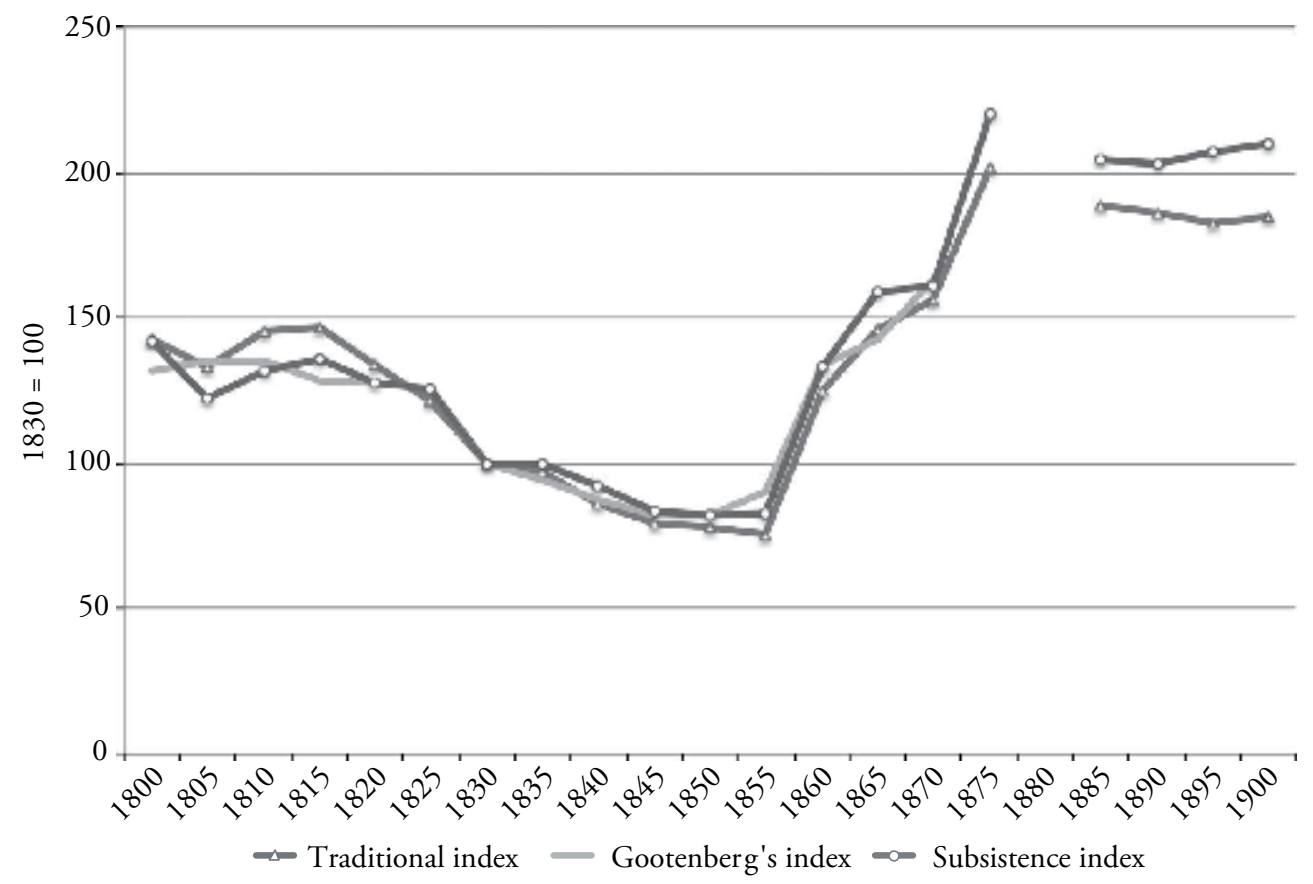

Fuentes: Para los índices de subsistencia y tradicionales, véase el texto; para el Índice de Gootenberg: Gootenberg (1990).

A partir de estas series, queda claro que el costo total de vida disminuyó a mediados del siglo XIX y aumentó considerablemente hasta la década de 1880 . A partir de mediados de los años 1870, los datos ahora disponibles corresponden a las series estimadas en este trabajo. Durante el resto del siglo, el costo de vida en Lima cayó ligeramente, permaneciendo en niveles significativamente más altos con respecto a los valores de mediados de siglo. En suma, la deflación fue frecuente después de las guerras de independencia seguida por un fuerte aumento generalizado en los precios de la década de 1850 y el siglo terminó con una deflación moderada. En general, el nivel de precios más que se duplicó en este siglo. Estos resultados se mantienen utilizando diferentes canastas de consumo del siglo XIX; la tendencia cíclica general se mantiene al variar las fuentes de proteínas y carbohidratos ${ }^{21}$. La tendencia descendente hasta mediados de siglo es impulsada principalmente por la evolución de los precios del pan y la mantequilla. A partir de este momento, la inflación se aceleró, especialmente en el periodo 1855-1870. El aumento de los precios fue tal que el gobierno nombró una comisión para analizar su evolución durante este periodo (véase Datos e informes, 1870). Este comité comentó la disparidad entre el patrón de consumo real observado y las posibles sustituciones nutricionales

${ }^{21}$ El costo de vida global es altamente sensible a la canasta de consumo de elección. En el Apéndice B, se presentan cuatro canastas de consumo adicionales con sus correspondientes series de costo de vida. 
disponibles para el público en general. La realidad, según este informe, era que la clase popular estaba tomando decisiones de consumo descuidadas. Dado el aumento del precio de la carne vacuna en relación con el precio del pescado, el consumo debería haberse desplazado hacia este último, teniendo especialmente en cuenta el contenido nutricional (Datos e informes 1870, pp. 100-105) 22 .

De acuerdo a los conocimientos médicos de la época, la comisión afirmó que a través de opciones más baratas, un «hombre podía hacer una libra de carne con su propio cuerpo" (Datos y reportes, 1870, p. 82). Aunque no hay estimaciones disponibles para el periodo de la guerra del Pacífico, diferentes fuentes indican un aumento dramático en los precios y una escasez generalizada de alimentos (véase, por ejemplo, Peloso, 1985). Hacia finales del siglo, los precios se estabilizaron, aunque a un nivel más alto en relación con las décadas anteriores.

\subsection{Salarios}

Para evaluar los niveles de vida, es necesario analizar la evolución de los salarios nominales en Lima durante este periodo. La literatura existente es escasa en esta área, ya que diversas fuentes proporcionan datos diferentes sobre los niveles salariales. Siguiendo la literatura existente sobre el nivel de vida de Allen et al. (2011), se han utilizado datos salariales para ocupaciones no calificadas. Específicamente, estos datos corresponden a ocupaciones que requieren poca o ninguna habilidad tales como vigilantes, guardias, porteros y sirvientes. Las fuentes de estos datos son similares a las utilizadas para los precios. En particular, he recopilado datos de organismos gubernamentales como el Ministerio de Hacienda, los tribunales inferiores, el Ministerio de Relaciones Exteriores y el Hospital Militar ${ }^{23}$. Adicionalmente se han consultado registros de instituciones privadas religiosas como Santa Clara y Trinitarias. Los datos provienen de registros contables que enumeran las ocupaciones y los salarios respectivos. En muchos casos, estos salarios son mensuales. En los registros eclesiásticos, algunos de los expedientes enumeraban a los trabajadores diarios ${ }^{24}$. Para convertir la serie en ganancias anuales,

\footnotetext{
22 El comité hace muchas sugerencias con respecto a la sustitución de alimentos basadas en el contenido nutricional. Los dos componentes analizados en términos de valor nutricional son el contenido de carbono y nitrógeno. Por ejemplo, el consumo del chayuyo, un tipo de alga marina, es altamente recomendado.

23 Archivo General de la Nación: OL 25 (Legajos 1-29), 35 (Legajo 3), 40 (Legajos 99-100), 71 (Legajos 42a, 383, 392), 104 (Legajo 18), 100 (Legajo 60), 152 (Legajos 1062. 1062a, 1071-1073,1077-8), 120 (Legajos 309, 325-331), 199 (Legajos 3867-4053, 4638-4674), 280 (Legajos 1996-2087),320 (Legajos 1267-1725), 359 (Legajos 497a, 497b, 498-637), 393 (Legajos 1145-1159), 431 (Legajos1314-1419), 432 (Legajos 1059-1084), 394 (1143-1159), 468 (Legajos 1-24, 35, 36), 472 (361-373,382-388), 502 (Legajos 638-647); RJ (Legajos 172, 259, 260), H-4 2152 (Legajo R.592), 2385, 2482, 2488, 2507, 2518, 3350, 4588. Archivo Histórico Militar: números 267, 432, 446, 450, 535, 572, 597, 668, 716, 720, 722, 749, 816. Arzobispado de Lima: véase nota al pie de página número 3.

${ }^{24}$ Los registros no incluían a los niños trabajadores. En algunos casos existían datos sobre las trabajadoras para las ocupaciones tradicionales como enfermera, cocinera y lavandera.
} 
se multiplicó el pago mensual por un factor de 12 y en el caso de un salario diario, el supuesto fue de 250-280 días al año (Brown, 1990; Johnson, 1990)25. Las series no son, por desgracia, continuas. Solo se han podido obtener datos cada cinco ańos y con una brecha importante durante la guerra del Pacífico ${ }^{26}$.

Teniendo en cuenta las limitaciones de los datos, es fundamental confirmar su vali$\mathrm{dez}^{27}$. Basadas en la composición de la fuerza de trabajo ofrecida por Hunt (1980), las fuentes de datos son representativas del mercado de trabajo de Lima: el gobierno y el sector de servicios empleaban casi el $40 \%$ de la fuerza de trabajo en $1876^{28}$. Desafortunadamente, los datos sobre los salarios en el siglo XIX son escasos ${ }^{29}$; Ruiz Zevallos (2001) reporta un salario promedio de 1,5 soles por día para un peón en una empresa manufacturera en 1900. Contreras (2004) y Giesecke (1978) publican que el salario no calificado era ligeramente inferior a un sol por día en 1866. En términos anuales, el promedio de estos datos está dentro de un rango del $10 \%$ con las series nominales presentadas aquí.

\subsection{COEFICIENTE DE BIENESTAR}

Con los salarios nominales y la estimación de la canasta básica para una familia de cuatro personas, es factible estimar el nivel de vida dividiendo el salario por la canasta de subsistencia. Esta relación se conoce en la literatura como el «coeficiente de bienestar». Una proporción de uno implica que el ingreso es suficiente para que una familia pueda subsistir. En consecuencia, un índice superior a uno sugiere que la familia podría permitirse otros bienes más allá de la canasta de subsistencia.

El Gráfico 2 muestra la evolución de esta relación a partir de 1820. Los datos muestran un patrón de $\mathrm{U}$ invertida: hay un aumento en el bienestar desde 1820 hasta mediados de siglo y una disminución a partir de entonces. La proporción aumenta de 1,5 en 1820 para alcanzar un máximo de casi 2,5 circa 1850 . Hacia finales del siglo, la relación se estabiliza alrededor del $10 \%$ por encima del nivel de subsistencia. El coeficiente de bienestar más bajo a partir de mediados de siglo en adelante y es el resultado de precios cada vez mayores y un salario nominal que no logró mantenerse al día con el costo de vida. En la década de 1860, la insatisfacción era palpable en la ciudad, donde los trabajadores a menudo se quejaban de los constantes aumentos de precios que afectaban a los alimentos básicos en sus dietas (Datos y reportes, 1870; Peloso, 1985).

\footnotetext{
25 Allen (2001) utiliza 250 días al ańo. Los datos recogidos reflejan principalmente pagos mensuales.

26 Según los archivistas del Archivo de la Nación, los registros de ese tiempo se perdieron, presumiblemente quemados por los chilenos durante la ocupación de Lima.

${ }^{27}$ Los datos salariales tienen limitaciones; por ejemplo, no tienen en cuenta los bienes producidos en el hogar. Contreras (2004) aborda esta cuestión manifestando que la estimación del valor de la producción doméstica en el Perú es muy difícil y hasta cierto punto inútil; no obstante, estima que podría ascender a $\$ 100$ por hogar por año.

${ }^{28}$ La fuerza de trabajo representaba el 48,8\% del total de la población (Hunt, 1980).

${ }^{29}$ Hunt (1980) publicó datos solamente sobre el siglo XX. Datos y reportes (1870) proporciona datos sobre los salarios de los esclavos en 1854 y los peones rurales en 1869 .
} 
Gráfico 2. Coeficiente de bienestar, décadas de 1820 a 1900

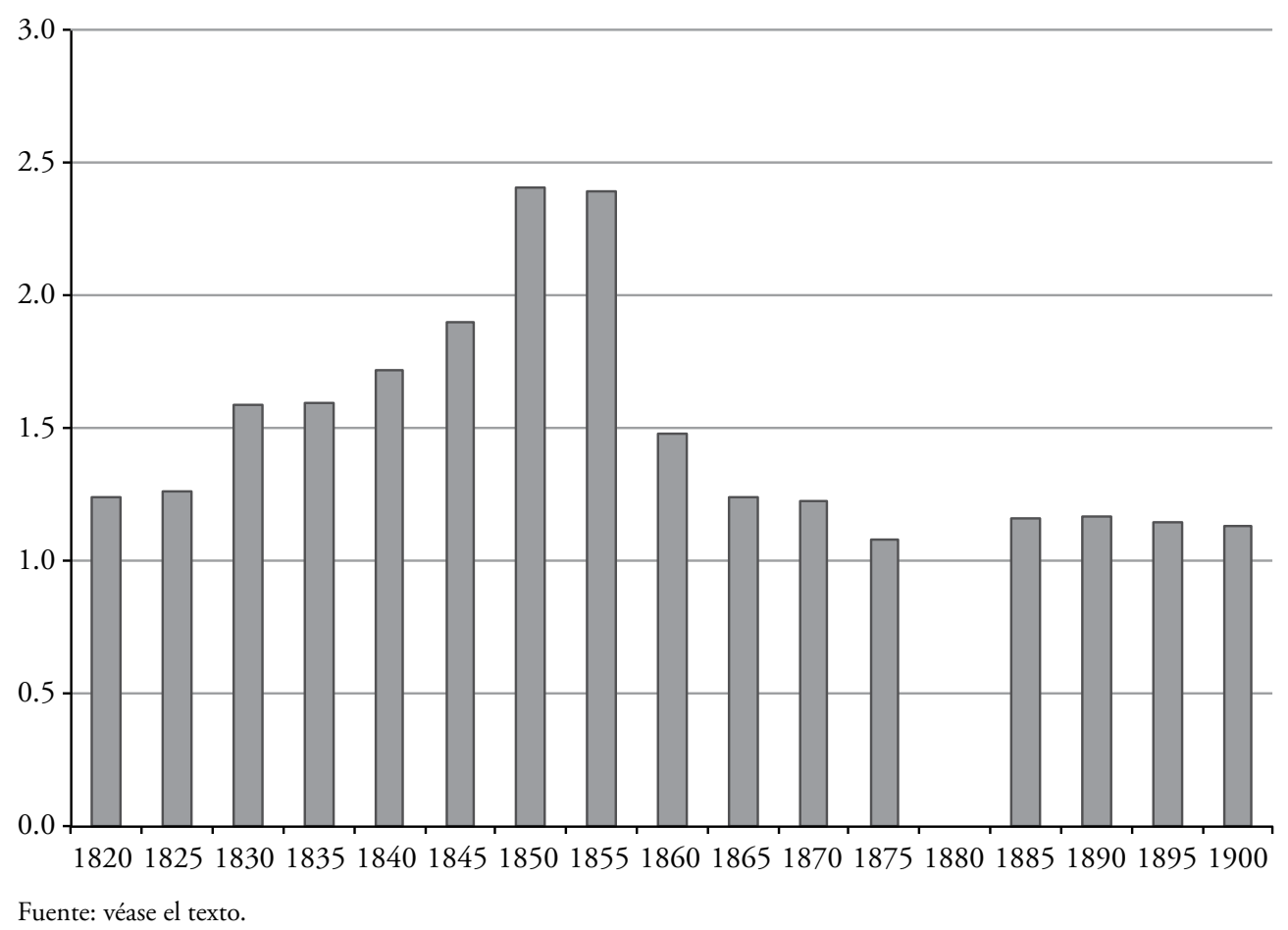

\section{COSTO DE VIDA Y ESTÁNDARES DE VIDA EN PERSPECTIVA HISTÓRICA E INTERNACIONAL}

Durante el siglo XIX, la economía peruana, después de la inestabilidad durante las gueras de independencia, experimentó un crecimiento sostenido gracias al auge del guano. En términos de nivel de vida, los primeros años de la independencia vieron una erosión del bienestar, siendo el coeficiente de bienestar solo $25 \%$ más alto que el nivel de subsistencia. Los niveles de vida mejoraron en las siguientes décadas, impulsados en gran parte por la continua deflación experimentada en ese periodo ${ }^{30}$. La explotación del guano tuvo un profundo impacto en la economía, contribuyendo a un aumento considerable del costo de vida en Lima (Giesecke, 1978; Gootenberg, 1990, 1993; Ponce Vega, 1993). La ciudad también actuó como un imán para las personas de otros lugares, lo que atrajo migrantes y aumentó la demanda (Klarén, 2005). La población de la ciudad creció casi un $70 \%$ durante 1836 y 1857 , desacelerándose durante el resto del siglo y llegando a más de 100000 en 1876 (Fuentes, 1858; Dirección de Estadística, 1878).

\footnotetext{
30 A pesar de la recuperación del dinamismo de la economía en la década de 1840, los precios continuaron cayendo según la medición de la canasta de subsistencia. Gootenberg (1990) también encuentra una tendencia deflacionista de magnitud similar en la década de 1840
} 
Los precios aumentaron más del $50 \%$ en la década de 1850 y continuaron esta tendencia en la década siguiente. El crecimiento implacable de los precios fue una fuente de preocupación tal que en 1870 se designó un comité para investigar sus causas. En este informe, el comité llegó a la conclusión de que la prosperidad era una de las principales causas de este fenómeno, como se manifestaba en el crecimiento de la población y el aumento en el retorno a la mano de obra y la tierra (Datos e Informes, 1870). Los niveles de vida mejoraron significativamente durante la década de 1850, ya que el coeficiente de bienestar aumentó a 2,4 y luego disminuyó continuamente en las décadas siguientes debido al rápido aumento de los precios (véase la Tabla 6).

Tabla 6. Índice de precios y coeficiente de bienestar

\begin{tabular}{l|c|c|c}
\hline & \multicolumn{3}{|c}{ Décadas } \\
\cline { 2 - 4 } & $\mathbf{1 8 2 0 - 1 8 4 0}$ & $\mathbf{1 8 5 0 - 1 8 7 0}$ & $\mathbf{1 8 8 0 - 1 8 9 0}$ \\
\hline $\begin{array}{l}\text { Indice de precios } \\
\quad \begin{array}{c}\text { Promedio, 1830=100 } \\
\text { Coeficiente de bienestar } \\
\text { Promedio }\end{array}\end{array}$ & 104 & 148 & 204 \\
\hline
\end{tabular}

Fuente: véase el texto. El índice de precios corresponde a la canasta de subsistencia.

El deterioro de los niveles de vida provocó descontento social que culminó en disturbios y levantamientos en la ciudad en 1858 y 1872 . En el caso de este último episodio, las raíces del descontento popular se remontan a políticas monetarias y fiscales expansionistas junto con un aumento de las importaciones, lo que se tradujo en un aumento en el costo de vida. Los precios de los principales productos de la canasta popular de consumo se habían más que duplicado en muchos casos (Giesecke, 1978; Gootenberg, 1990; Klarén, 2005). Según Giesecke (1978, p. 114), «la situación socioeconómica de los más pobres era muy dura y generaba un alto grado de descontento [...]. La situación social fue, en consecuencia, explosiva".

Las secuelas de la crisis económica y la guerra provocaron un largo periodo de deflación en la economía peruana. El costo de vida cayó sustancialmente, pero permaneció más alto que durante la era anterior al guano. Esta era una buena noticia en términos del nivel de vida, que ganó un poco de terreno en comparación con 1875. Con el cambio de siglo, Perú había sobrevivido a un importante auge de los productos básicos y a una guerra. En términos de PBI per cápita, el habitante promedio era $70 \%$ más rico que en los primeros tiempos independientes, pero desde el punto de vista del estándar de vida, el trabajador no calificado estaba en peor situación. Utilizando el coeficiente de bienestar, la pérdida fue de $10 \%$ en comparación con 1825 .

El auge y la caída del nivel de vida en el Perú del siglo XIX muestran una desconexión entre el crecimiento económico y el nivel de vida, especialmente durante el auge del guano. 
Hasta ahora la literatura muestra un patrón en forma de U invertida para el Perú durante el siglo XIX: hubo poco crecimiento en las dos décadas posteriores a la independencia, seguido por un rápido crecimiento durante la era del guano ${ }^{31}$. El desempeńo durante el resto del siglo XIX estuvo marcado por una caída considerable del crecimiento económico antes y después de la guerra del Pacífico y una vigorosa recuperación en la década de 1890. El PBI per cápita alcanzó su máximo en 1876 de \$ 1123 y 7 años más tarde era solamente de $\$ 477$ (dólares de Geary-Khamis). Muchos autores han notado esta experiencia de montańa rusa en la historia peruana, indicando el fracaso del país en lograr desarrollo y crecimiento económico sustentables.

Tabla 7. Estándares de vida alrededor del mundo, circa 1820

\begin{tabular}{l|c|c}
\hline & Año & Ratio \\
\hline Amsterdam & 1820 & 1,76 \\
Gdansk & 1812 & 1,06 \\
Krakow & 1820 & 1,03 \\
Londres & 1820 & 2,19 \\
Madrid & 1820 & 1,77 \\
Milan & 1820 & 0,61 \\
Estrasburg & 1820 & 1,61 \\
Varsovia & 1820 & 1,67 \\
\hline Beijing & 1820 & 1,09 \\
Kyoto/Tokio & 1820 & 0,93 \\
India - norte & 1820 & 1,68 \\
\hline Bogotá & 1800 & 1,45 \\
Buenos Aires & 1827 & 3,39 \\
Caracas & 1830 & 0,34 \\
Lima & 1820 & 1,23 \\
México & 1810 & 0,93 \\
Potosí & 1810 & 1,65 \\
\hline
\end{tabular}

Fuentes: Buenos Aires, Bogotá, y México: Arroyo Abad et al. (2012); Caracas: Arroyo Abad (2013), Europa: Allen (2001); India: Allen (2007); Beijing y Tokio: Allen et al. (2011).

Si bien la trayectoria del PBI per cápita es informativa, el PIB per cápita per se es un indicador imperfecto de bienestar económico por muchas razones; por ejemplo, solo toma en cuenta la actividad del mercado y es invariante con respecto a la calidad de los bienes y servicios tratados. Más relevante para esta discusión es que el PBI per cápita no proporciona información sobre la distribución del ingreso ${ }^{32}$.

\footnotetext{
31 Con las notables excepciones de Basadre (1969) y Levin (1960); ambos afirman que el crecimiento económico no se materializó durante la era del guano.

32 Muchas fuentes discuten las limitaciones del PBI y el PBI per cápita, comenzando con los libros de texto de macroeconomía. Bértola et al. (2011) analiza este tema para América Latina en el siglo XX.
} 
Gráfico 3. Estándares de vida en Lima, Caracas, Beijing, Londres y Madrid, siglo XIX

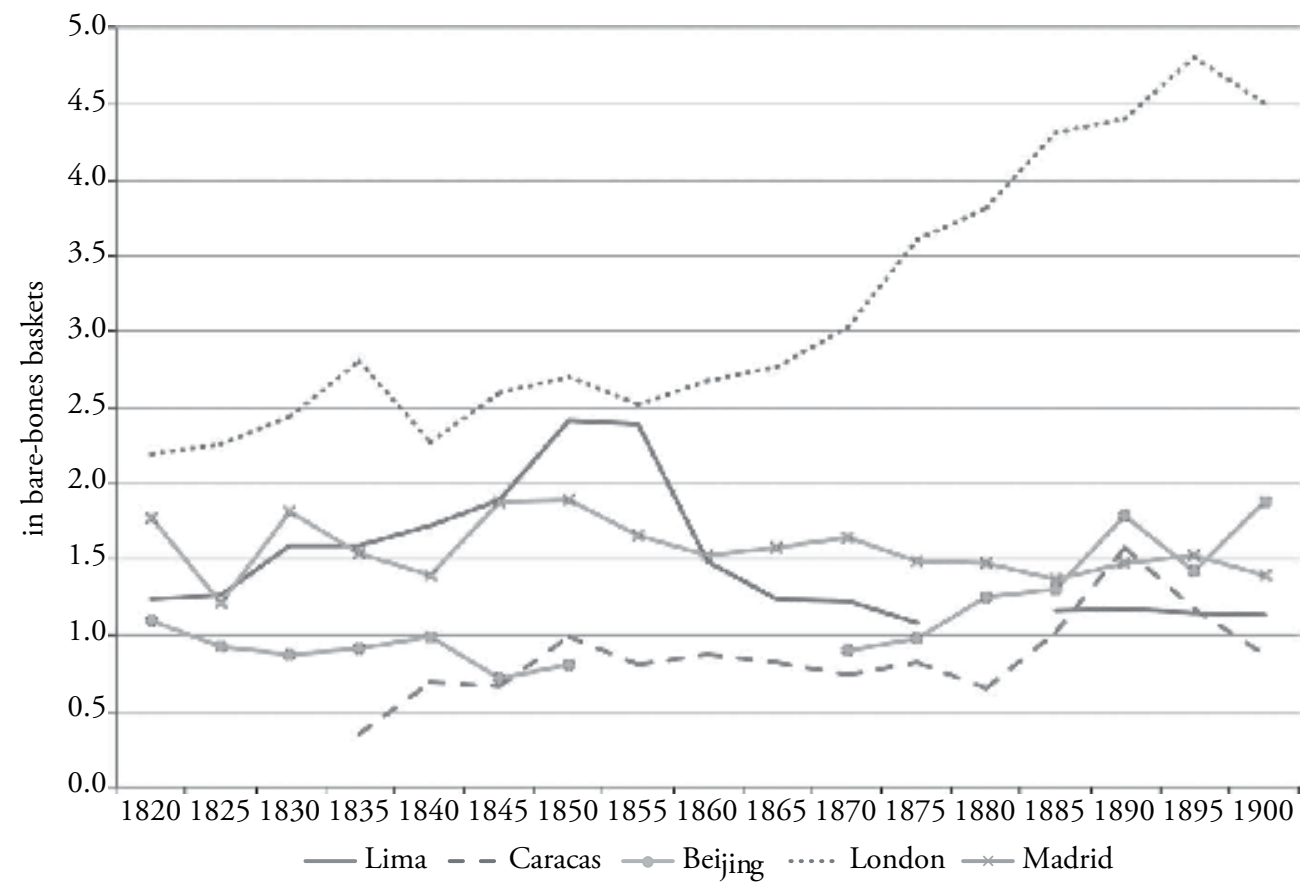

Fuentes: Lima: véase texto; Caracas: Arroyo Abad (2013), Beijing: Allen et al. (2011), Madrid y Londres: Allen (2001).

La historia de rápido enriquecimiento muestra una trayectoria diferente cuando se mira el bienestar de la clase popular, con un máximo de 2,4 canastas de subsistencia alcanzadas a mediados del siglo XIX y seguidas por una disminución para el resto del siglo. La diferencia entre la evolución del nivel de vida y el crecimiento económico sugiere que los beneficios del auge del guano fueron aún más limitados para la clase popular. Contemporáneos y estudiosos reconocieron la polarización económica sin precedentes durante el auge del guano, por ejemplo Wiener (1880, p. 41) afirmó que la sociedad peruana estaba dividida en dos grupos: «dinero y conocimiento» en un extremo y "pobreza e ignorancia» en el otro. La afluencia de ingresos del guano amplió la brecha entre ricos y pobres, ya que la inflación erosionó los salarios reales (Gootenberg, 1989, 1993; Klarén, 2005). La evidencia antropométrica es consistente con estos resultados.

Twrdek y Manzel (2010) concluyeron que los efectos positivos del auge del guano no llegaron a las clases populares. El uso de la metodología de Allen (2001) permite la comparación internacional. Gracias al trabajo diligente de muchos historiadores económicos, es posible realizar comparaciones con una selección de ciudades durante el siglo XIX ${ }^{33}$. La Tabla 7 ofrece estimaciones del estándar de vida circa la década de 1820

33 Para las series de datos, véase la página web del Global Prices and Income History Group (http://gpih. ucdavis.edu). 
para diecisiete ciudades, cinco de ellas en América Latina. El índice de bienestar de Lima está en el promedio para la región pero es inferior a las cifras europeas.

Desde una perspectiva más dinámica, el auge del guano colocó a Lima en un estándar de vida más alto durante una década (ver Gráfico 3). Esta escalada impresionante elevó el nivel de vida de Lima a niveles similares a los de Londres. Sin embargo, fue acompañado por una fuerte caída, cayendo a casi nivel de subsistencia, terminando el siglo con niveles de vida más bajos que Caracas.

\section{COMENTARIOS A MODO DE CONCLUSIÓN}

A lo largo del siglo XIX Perú enfrentó los desafíos asociados con la transición del sistema colonial. Después de la lucha de las primeras décadas independientes, siguió una nueva era próspera, donde un solo producto de exportación, el poderoso fertilizante del guano, alimentó la economía e inundó las arcas públicas. A principios de la década de 1870, la conjunción de reservas cada vez más reducidas, nuevos fertilizantes artificiales y una guerra con una nación vecina pusieron fin a esta era de abundancia. En general, este siglo fue una montańa rusa de crecimiento económico en la que, como muchos estudiosos han señalado, la oportunidad de crecimiento sostenible fue malgastada.

En este trabajo se analizó cómo el costo de vida y el nivel de vida de Lima, Perú, se corresponden con los cambios económicos experimentados en el siglo XIX. Utilizando una serie de fuentes de archivo, se han estimado dos índices de precios, una canasta de subsistencia siguiendo la metodología de Allen (2001) y una más completa comparable al presupuesto de Gootenberg (1990). Estas nuevas series de datos muestran un periodo deflacionario después de las guerras de independencia, seguido por un fuerte aumento en los precios durante el auge del guano. Después de una caída después de la guerra del Pacífico, el nivel de precios del Perú se estabilizó hacia fines de siglo. Los estándares de vida mejoraron hacia mediados de siglo; sin embargo, el proceso inflacionario erosionó estas ganancias en la década de 1870 .

Dado que el PBI per cápita se incrementó hasta principios de la década de 1870, estos resultados sugieren que las ganancias del auge del guano estuvieron sesgadas hacia la élite, especialmente después de la década de 1850. Las clases populares no se beneficiaron plenamente del crecimiento económico.

Como indican los estudios del agotamiento del modelo de guano a comienzos de la década de 1870, esta nueva investigación muestra que la empresa más rentable del Perú no logró que las clases populares escaparan el nivel de consumo de subsistencia por mucho tiempo. Estos resultados están en línea con los estudios que destacan la base institucional débil en este país. El advenimiento de la bonanza del guano como la principal fuente de ingresos para el Perú en una etapa tan temprana de su nacionalidad sepultó la necesidad de construir una estructura económica más diversificada y la búsqueda de fuentes diferentes de ingresos fiscales. 


\section{Apéndice A. Conversiones al sistema métrico}

La mayor parte de los precios fueron listados en unidades no métricas. Siguiendo a Descola (1962), Gootenberg (1990) y Langer y Hames (1994), las conversiones usadas son las siguientes:

$$
\begin{aligned}
& 1 \text { arroba }=25 \mathrm{lbs}=11,36 \mathrm{~kg} \\
& 1 \text { quintal }=4 \text { arrobas }=45,44 \mathrm{~kg} \\
& 1 \text { fanega de maíz o trigo }=61,36 \mathrm{~kg} \\
& 1 \text { fanega of frijol }=70,90 \mathrm{~kg} \\
& 1 \text { saco de harina o garbanzo }=90,90 \mathrm{~kg} \\
& 1 \text { saco de maíz }=70 \mathrm{~kg} \\
& 1 \text { carga }=45,44 \mathrm{~kg} \\
& 1 \mathrm{lb}=0,45 \mathrm{~kg} \\
& 1 \text { cántara }=8 \text { azumbres }=2,5 \text { galones } \\
& 1 \text { vara }=3 \text { pies }=0,91 \mathrm{~m}
\end{aligned}
$$

\section{Apéndice B. Ejercicios de consistencia}

La construcción de índices históricos de costo de vida es un desafío, ya que requiere un conocimiento confiable de la canasta de consumo típica para una ciudad determinada durante un periodo de tiempo. Afortunadamente, para el Perú del siglo XIX hay muchas fuentes que documentan los patrones de consumo, en particular para Lima. A pesar de que el costo de vida en este artículo se basa en una canasta específica definida por Peloso (1985), es importante ejecutar controles de consistencia en forma de canastas alternativas. Este ejercicio permitirá asegurar la fiabilidad de la canasta elegida en términos de patrones generales de costo de vida. Obsérvese que las canastas de consumo utilizadas son, en su mayoría, representativas de los patrones de consumo de la clase popular.

En concreto, las canastas escogidas corresponden a un individuo de bajos ingresos como lo presenta Gootenberg (1990), un prisionero según lo informado por el Ayuntamiento de Lima (Consejo de 1889) y tres canastas de consumo del informe sobre la inflación en Lima en 1870, correspondiente a un prisionero, un esclavo y un oficial del ejército (Datos e informes, 1870). Estas estimaciones se comparan con los índices estimados en este artículo, es decir, los de subsistencia y los tradicionales. La Tabla B1 muestra la composición de cada canasta comenzando con la canasta de subsistencia introducida en este artículo. Con la excepción de la canasta de los esclavos, todas las demás canastas tienen un consumo mucho mayor de carne, hasta $167,9 \mathrm{~kg}$ por año. Esta cifra parece ser demasiado alta, ya que el consumo per cápita de carne era de alrededor de $98 \mathrm{~kg}$, lo que coincide con la cifra utilizada en la canasta de subsistencia basada en Peloso (1985). En cuanto al total de calorías por canasta, es evidente que todas estas canastas están muy por encima del umbral de subsistencia. Por ejemplo, la canasta de Gootenberg (1990) añade al menos 3000 calorías, muy por encima de la canasta «respetable» ideada por Allen (2001). 
Tabla B1. Canastas de consumo seleccionadas

\begin{tabular}{|c|c|c|c|c|c|c|c|}
\hline & \multicolumn{7}{|c|}{ Composición de la canasta por año } \\
\hline & Unidad & Subsistencia & Gootenberg $^{1}$ & $\begin{array}{c}\text { Prisionero } \\
1\end{array}$ & Esclavo & $\begin{array}{c}\text { Prisionero } \\
2\end{array}$ & $\begin{array}{l}\text { Oficial del } \\
\text { Ejército }\end{array}$ \\
\hline \multicolumn{8}{|l|}{ Alimento } \\
\hline Carnes & $\mathrm{kg}$ & 98,2 & 167,9 & 124,4 & & 167,9 & 126,1 \\
\hline Pan & $\mathrm{kg}$ & 49,1 & 104,8 & 41,5 & 167,9 & 147,2 & 87,6 \\
\hline Arroz & $\mathrm{kg}$ & 58,9 & 62,8 & 83,0 & & 52,6 & 61,3 \\
\hline Frijol & $\mathrm{kg}$ & 49,1 & 42,0 & 62,2 & 167,9 & 63,1 & 61,3 \\
\hline Manteca & $\mathrm{kg}$ & & 20,8 & & & & \\
\hline Manteq. & $\mathrm{kg}$ & 11,8 & & 5,2 & & & 10,5 \\
\hline Papas & $\mathrm{kg}$ & & & 2,1 & & & 92,0 \\
\hline \multicolumn{8}{|l|}{ Otros } \\
\hline Algodón & M & 3 & & 3 & 3 & 3 & 3 \\
\hline Combust & M BTU & 3 & $167,9^{*}$ & 3 & 3 & 3 & 3 \\
\hline Velas & $\mathrm{kg}$ & 1,3 & & 1,3 & 1,3 & 1,3 & 1,3 \\
\hline Jabón & $\mathrm{kg}$ & 1,3 & & 1,3 & 1,3 & 1,3 & 1,3 \\
\hline
\end{tabular}

Notas: M: metro; M BTU: millones de BTU.

*Kilogramos.

${ }^{1}$ La canasta de Gootenberg incluye otros ítems como azúcar, leche, té, vinagre y sal. Véase Gootenberg (1990, p. 14), para los detalles.

Fuentes: subsistencia, véase el texto; Gootenberg: Gootenberg (1990), Prisionero (1): Concejo Provincial de Lima (1889); Esclavo: Prisionero (2), y Oficial del Ejército: Datos e informes (1870).

Las diferencias entre estas canastas proporcionan la oportunidad de evaluar las tendencias generales del nivel de precios. El Gráfico B1 muestra la evolución de estos índices de costo de vida en el tiempo con base $1830=100^{34}$. A primera vista, las tendencias son similares con una fase deflacionaria hasta la década de 1850 y un periodo inflacionario hasta la década de 1870. Este hecho se corrobora con los correspondientes coeficientes de correlación, que oscilan entre 0,74 y 0,99 . El costo de vida de los oficiales del ejército aparece como el más disímil de la muestra, a la par que la serie se rebasa antes de la guerra del Pacífico. Este movimiento se explica plenamente por el fuerte aumento en el precio de las papas debido a una peste generalizada que afectó a este cultivo a finales de 1860 y principios de 1870 .

34 Obsérvese que la canasta de consumo de un esclavo se calculó después de 1854, cuando se abolió la esclavitud en Perú, con fines ilustrativos. 
Gráfico B1. Índices de costo de vida, $1830=100$

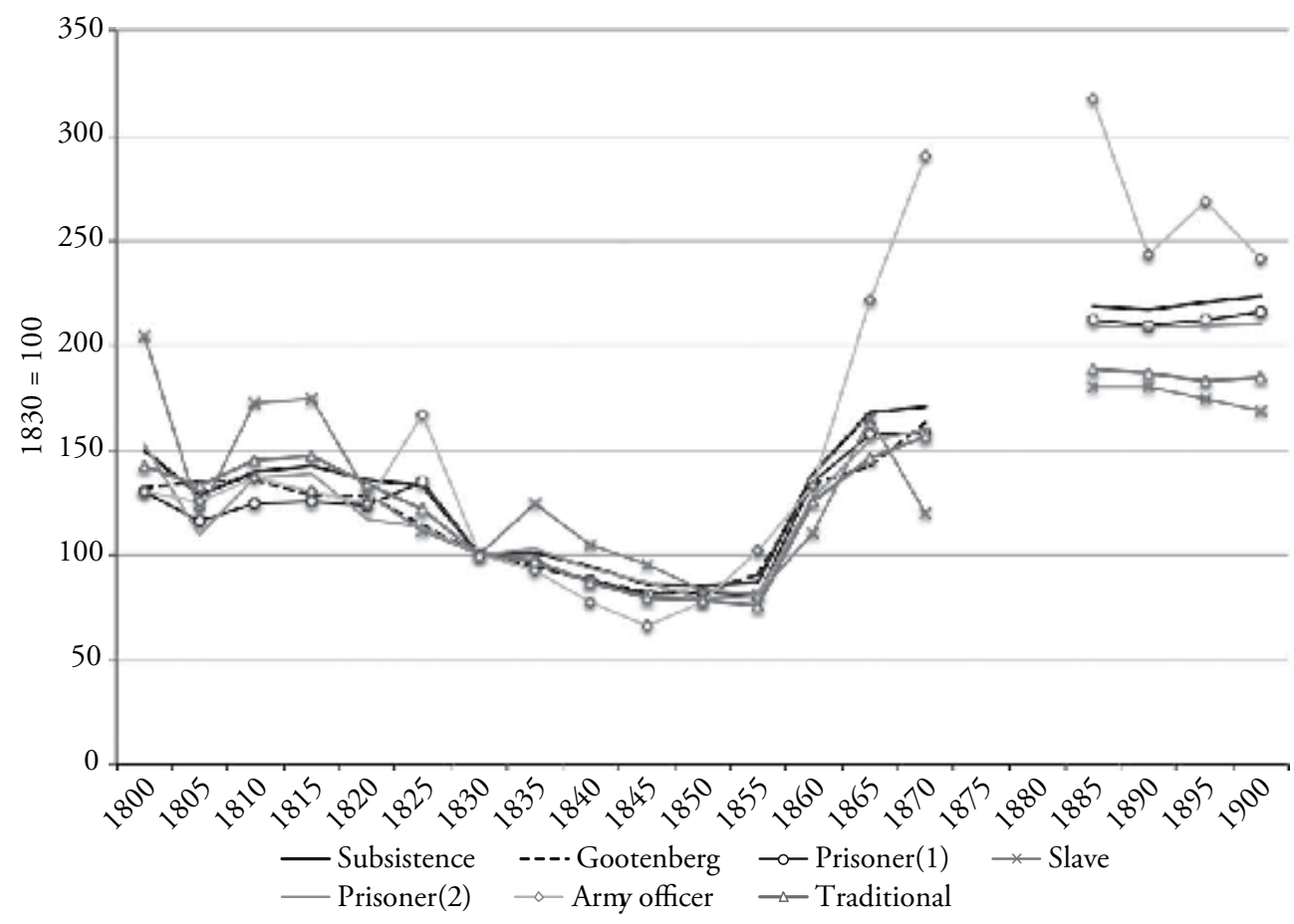

Apéndice C. Series de datos

\begin{tabular}{l|c|c|c|c}
\hline \multirow{2}{*}{} & \multicolumn{3}{|c|}{ Costo de vida } & Estándares de vida \\
\cline { 2 - 5 } & $\begin{array}{c}\text { Índice de subsistencia } \\
(\mathbf{1 8 3 0}=\mathbf{1 0 0})\end{array}$ & $\begin{array}{c}\text { Índice } \\
\text { tradicional }\end{array}$ & $\begin{array}{c}\text { Índice de } \\
\text { Gootenberg }\end{array}$ & $\begin{array}{c}\text { Coeficiente de bienestar } \\
(\mathbf{1} \text { = subsistencia) }\end{array}$ \\
\hline 1800 & 141,8 & 142,8 & 131,8 & \\
1805 & 122,6 & 133,0 & 135,2 & \\
1810 & 132,2 & 145,3 & 135,4 & \\
1815 & 135,0 & 146,9 & 128,7 & 1,2 \\
1820 & 128,9 & 134,1 & 127,9 & \\
1821 & 129,9 & & & \\
1822 & 144,9 & 146,9 & 164,0 & \\
1823 & 139,9 & & & 1,3 \\
1824 & 128,1 & & & \\
1825 & 126,3 & 121,4 & 112,7 & \\
1826 & 108,8 & 118,5 & 105,9 & \\
1827 & 11,7 & 113,7 & 102,3 & \\
1828 & 107,5 & 106,1 & 1,6 \\
1829 & 105,1 & 104,4 & 98,3 & \\
1830 & 100,0 & 100,0 & 100,0 & \\
1831 & 102,2 & 100,4 & 96,7 &
\end{tabular}




\begin{tabular}{|c|c|c|c|c|}
\hline & \multicolumn{3}{|c|}{ Costo de vida } & \multirow{2}{*}{$\begin{array}{c}\text { Estándares de vida } \\
\text { Coeficiente de bienestar } \\
(1=\text { subsistencia })\end{array}$} \\
\hline & $\begin{array}{l}\text { Índice de subsistencia } \\
\qquad(1830=100)\end{array}$ & $\begin{array}{l}\text { Índice } \\
\text { tradicional }\end{array}$ & $\begin{array}{l}\text { Índice de } \\
\text { Gootenberg }\end{array}$ & \\
\hline 1832 & 94,2 & 93,6 & 92,1 & \\
\hline 1833 & 100,9 & 99,3 & 100,4 & \\
\hline 1834 & 99,6 & 97,6 & 94,7 & \\
\hline 1835 & 99,6 & 97,1 & 94,4 & 1,6 \\
\hline 1836 & 111,3 & 105,0 & 101,2 & \\
\hline 1837 & 112,3 & 103,8 & 103,3 & \\
\hline 1838 & 106,2 & 98,4 & 103,2 & \\
\hline 1839 & 103,8 & 97,2 & 102,8 & \\
\hline 1840 & 92,3 & 86,6 & 88,0 & 1,7 \\
\hline 1841 & 89,1 & 84,7 & 86,9 & \\
\hline 1842 & 88,2 & 83,1 & 82,0 & \\
\hline 1843 & 83,8 & 79,6 & 80,6 & \\
\hline 1844 & 83,8 & 79,6 & 82,2 & \\
\hline 1845 & 83,8 & 79,3 & 82,0 & 1,9 \\
\hline 1846 & 83,6 & 78,6 & 81,5 & \\
\hline 1847 & 92,0 & 85,5 & 86,8 & \\
\hline 1848 & 85,8 & 79,6 & 80,9 & \\
\hline 1849 & 85,6 & 78,2 & 82,5 & \\
\hline 1850 & 82,1 & 78,5 & 82,1 & 2,4 \\
\hline 1851 & 83,4 & 80,0 & 84,2 & \\
\hline 1852 & 83,1 & 80,2 & 85,6 & \\
\hline 1853 & 84,3 & 77,9 & 83,9 & \\
\hline 1854 & 81,2 & 75,0 & 81,2 & \\
\hline 1855 & 82,5 & 75,8 & 90,2 & 2,4 \\
\hline 1856 & 94,9 & 83,9 & 109,1 & \\
\hline 1857 & 94,8 & 84,7 & 108,4 & \\
\hline 1858 & 95,4 & 84,8 & 110,2 & \\
\hline 1859 & 116,8 & 109,8 & 104,1 & \\
\hline 1860 & 132,3 & 125,0 & 134,2 & 1,5 \\
\hline 1861 & 137,9 & 124,4 & 121,7 & \\
\hline 1862 & 149,3 & 126,9 & 121,4 & \\
\hline 1863 & 149,3 & 120,2 & 120,9 & \\
\hline 1864 & 144,4 & 126,2 & 129,4 & \\
\hline 1865 & 157,8 & 146,3 & 142,6 & 1,3 \\
\hline 1866 & 154,0 & 147,0 & 154,1 & \\
\hline 1867 & 154,5 & 145,7 & 157,2 & \\
\hline 1868 & 155,1 & 145,5 & 158,8 & \\
\hline 1869 & 169,3 & 159,0 & 160,0 & \\
\hline 1870 & 165,8 & 156,3 & 162,9 & 1,2 \\
\hline 1871 & 206,2 & 188,8 & 164,3 & \\
\hline 1872 & 222,4 & 206,2 & 168,4 & \\
\hline 1873 & 220,3 & 205,4 & 172,7 & \\
\hline
\end{tabular}




\begin{tabular}{|c|c|c|c|c|}
\hline & \multicolumn{3}{|c|}{ Costo de vida } & \multirow{2}{*}{$\begin{array}{c}\text { Estándares de vida } \\
\text { Coeficiente de bienestar } \\
(1=\text { subsistencia })\end{array}$} \\
\hline & $\begin{array}{l}\text { Índice de subsistencia } \\
\qquad(1830=100)\end{array}$ & $\begin{array}{l}\text { Índice } \\
\text { tradicional }\end{array}$ & $\begin{array}{c}\text { Índice de } \\
\text { Gootenberg }\end{array}$ & \\
\hline 1874 & 218,9 & 203,4 & & \\
\hline 1875 & 216,9 & 202,3 & & 1,1 \\
\hline 1876 & 216,3 & 200,5 & & \\
\hline 1877 & 215,1 & 200,1 & & \\
\hline 1878 & 215,3 & 199,1 & & \\
\hline 1879 & & & & \\
\hline 1880 & & & & \\
\hline 1881 & & & & \\
\hline 1882 & & & & \\
\hline 1883 & & & & \\
\hline 1884 & 216,9 & 192,2 & & \\
\hline 1885 & 201,4 & 188,9 & & 1,2 \\
\hline 1886 & 202,3 & 188,3 & & \\
\hline 1887 & 202,7 & 189,1 & & \\
\hline 1888 & 202,8 & 189,2 & & \\
\hline 1889 & 202,1 & 189,3 & & \\
\hline 1890 & 199,9 & 186,7 & & 1,2 \\
\hline 1891 & 201,4 & 186,9 & & \\
\hline 1892 & 203,0 & 187,2 & & \\
\hline 1893 & 202,5 & 187,5 & & \\
\hline 1894 & 202,8 & 187,1 & & \\
\hline 1895 & 204,1 & 182,8 & & 1,2 \\
\hline 1896 & 202,7 & 182,2 & & \\
\hline 1897 & 201,9 & 182,6 & & \\
\hline 1898 & 202,5 & 182,3 & & \\
\hline 1899 & 204,3 & 182,8 & & \\
\hline 1900 & 207,1 & 184,8 & & 1,1 \\
\hline 1891 & 201,4 & 186,9 & & \\
\hline 1892 & 203,0 & 187,2 & & \\
\hline 1893 & 202,5 & 187,5 & & \\
\hline 1894 & 202,8 & 187,1 & & \\
\hline 1895 & 204,1 & 182,8 & & 1,2 \\
\hline 1896 & 202,7 & 182,2 & & \\
\hline 1897 & 201,9 & 182,6 & & \\
\hline 1898 & 202,5 & 182,3 & & \\
\hline 1899 & 204,3 & 182,8 & & \\
\hline 1900 & 207,1 & 184,8 & & 1,1 \\
\hline
\end{tabular}

Fuente: véase el texto. 


\section{REFERENCIAS BIBLIOGRÁFICAS}

Allen, R. (2001). The Great Divergence in European Wages and Prices from the Middle Ages to the First World War. Explorations in Economic History, 38, 411-447. https://doi. org/10.1006/exeh.2001.0775

Allen, R. (2007). India in the Great Divergence. En Timothy Hatton, Kevin O'Rourke y Alan Taylor (eds.), The New Comparative Economic History (pp. 9-32). Cambridge: MIT Press.

Allen, R. J., D. M. A. Bassino, C. Moll-Murata y J. L. Van Zanden (2011). Wages, Prices, and Living Standards in China, 1738-1925: In Comparison with Europe, Japan, and India. Economic History Review. 64(1), 8-38.

Arroyo Abad, L. (2013). Inestabilidad, bienestar económico y costo de vida en Venezuela durante el siglo XIX. América Latina en la Historia Económica, 20(3), 114-137. https://doi. org/10.18232/alhe.v20i3.551

Arroyo Abad, L., E. Davies y J. L. Van Zanden (2012). Between Conquest and Independence: Real wages and demographic change in Spanish America, 1530-1820. Explorations in Economic History, 49(2), 149-166. https://doi.org/10.1016/j.eeh.2011.12.001

Basadre, J. (1969). Historia de la República de Perú. Lima: Editorial Universitaria.

Bértola, L. (ed.) (2000). Ensayos de historia económica: Uruguay y la región en la economía mundial, 1870-1900. Montevideo: Ediciones Trilce.

Bértola, L., M. Hernández, J. Rodríguez Weber y S. Siniscalchi (2011). «Siglo de Desarrollo Humano y Desigualdad». Mimeo, Programa de Historia Económica y Social.

Bonilla, H. (1974). Guano y burguesía en el Perú. Lima: Instituto de Estudios Peruanos.

Braun, J., M. Braun, I. Briones y J. Díaz (2000). Estadísticas históricas de la economía chilena, 1810-1995. IEUC Documentos de Trabajo. 187.

Brown, K. (1990). Price Movements in Eighteenth-Century Peru: Arequipa. En L. L. Johnson y E. Tandeter (eds.), Essays on the Price History of Eighteenth-Century Latin America (pp. 173-200). Albuquerque: University of New Mexico Press.

Concejo Provincial de Lima (1889). Memoria de la Administración. Lima: Imprenta Solís.

Contreras, C. (2004). El aprendizaje del capitalismo: estudios de historia económica y social del Perú republicano. Lima: Instituto de Estudios Peruanos.

Contreras, C. (2012). La economía pública en el Perú después del guano y del salitre. Lima: Banco Central de Reserva del Perú.

Contreras, C. y M. Cueto (2004). Historia del Perú contemporáneo. Lima: Instituto de Estudios Peruanos.

Cuesta, E. (2007). Precios y mercados en Buenos Aires en el siglo XVIII. América Latina en la Historia Económica, 14(2), 25-57. https://doi.org/10.18232/alhe.v14i2.314

Cuesta, E. (2012). Precios y salarios en Buenos Aires durante la Gran Expansión (1850-1914). Revista de Instituciones, Ideas y Mercados, 56, 159-179.

Cuesta, M., I. Moras y C. Newland (2011). Prices, Wages and Economic Change. The Espacio Peruano Region, 1591-1790. Anuario de Estudios Bolivianos, Archivisticos y Bibliográficos, $16,311-325$.

Cvrcek, T. (2013). Wages, Prices, and Living Standards in the Habsburg Empire, 1827-1900. Journal of Economic History, 73(1), 1-30. https://doi.org/10.1017/S0022050713000016

Dancuart, P. E. (1905). Anales de la Hacienda Pública del Perú: Historia y Legislación Fiscal de la República. Lima: Librería e Imprenta Gil.

Datos e Informes (1870). Datos e Informes sobre las causas que han producido el alza de precios de los artículos de primera necesidad que se consumen en la capital. Lima: Imprenta del Estado. 
Descola, J. (1962). Daily Life in Colonial Peru, 1710-1820. Nueva York: Macmillan Company. Deustua, J. (1986). La minería peruana y la iniciación de la República, 1820-1840. Lima: Instituto de Estudios Peruanos.

Deustua, J. (2000). The Bewitchment of Silver: The Social Economy of Mining in Nineteenth-Century Peru. Athens: Ohio University Center for International Studies.

Dirección de Estadística (1878). Censo General de la República de Perú. Lima: Imprenta del Teatro.

Florescano, E. (1968). La historia de los precios en la época colonial de Hispanoamérica: Tendencias, métodos de trabajos y objetivos. Anuario de Estudios Latinoamericanos, 1, 11-129.

Fuentes, M. (1858). Estadistica General de Lima. Lima: Tip. Nacional M. N. Corpancho.

Giesecke, M. (1978). Masas urbanas y rebelión en la historia: golpe de Estado: Lima 1872. Lima: Cedhip.

Gómez-Galvarriato, A. y Musacchio, A. (2000). Un nuevo índice de precios para México, 18861929. El Trimestre Económico, enero-marzo, 47-91.

Gootenberg, P. (1989). Between Silver and Guano: Commercial Policy and the State in Postindependence Peru. Princeton: Princeton University Press.

Gootenberg, P. (1990). Carneros y Chuño: Price Levels in Nineteenth-Century Peru. The Hispanic American Historical Review, 70(1), 1-56. https://doi.org/10.2307/2516366

Gootenberg, P. (1993). Imagining Development: Economic ideas in Peru's "Fictitious Prosperity» of Guano, 1840-1880. Berkeley: University of California Press.

Hanes, M. R. (2006). Wholesale Prices of Selected Commodities: 1784-1998. Table Cc205-266. En S. B. Carter, S. Gartner, M. R. Haines, A. L. Olmstead, R. Sutch y G. Wright (eds.), Historical Statistics of the United States, Earliest Times to the Present: Millennial Edition. Nueva York: Cambridge University Press. https://doi.org/10.1017/ISBN-9780511132971. Cc205-266

Hunt, S. (1973). Price and Quantum Estimates of Peruvian Exports, 1830-1962. Research Program in Economic Development Discussion Paper No. 33.

Hunt, S. (1980). Evolución de los salarios reales en el Perú: 1900-1940. Economía, 3(5), 83-123.

Hunt, S. (1984). Guano y crecimiento en el Perú del siglo XIX. HISLA: Revista Latinoamericana de la historia Económica y Social, 4, 35-92.

Hunt, S. (1996). The Current Economic Situation in Long-Term Perspective. En E. Gonzalez de Olarte (ed.), The Peruvian Economy and Structural Adjustment: Past, Present, and Future. Coral Gables: University of Miami.

Hunt, S. (2011). La formación de la economia peruana: Distribución y crecimiento en la historia del Perú y América Latina. Lima: Instituto de Estudios Peruanos.

Johnson, L. L. (1990). The Price History of Buenos Aires during the Viceregal Period. En L. L. Johnson y E. Tandeter (eds.), Essays on the Price of History of Eighteenth-Century Latin America. Albuquerque: University of New Mexico Press.

Johnson, L. L. (1992). Perspectivas encontradas: Romano, Johnson y la historia de precios del Buenos Aires virreinal. Boletín del Instituto de Historia Argentina y Americana «Dr. E. Ravignani», 6, 163-172.

Johnson, L. L. y E. Tandeter (eds.) (1990). Essays on the Price of History of Eighteenth-Century Latin America. Albuquerque: University of New Mexico Press.

Klarén, P. (2005). Nación y sociedad en la historia del Perú. Lima: Instituto de Estudios Peruanos. Langer, E. y G. L. Hames (1994). Commerce and Credit on the Periphery: Tarija Merchants, 1830-1914. The Hispanic American Historical Review, 74(2), 285-316. https://doi. org/10.2307/2517566 
Levin, J. (1960). The Export Economies. Cambridge: Harvard University Press.

Macera, P. (1974). Las plantaciones azucareras en el Perú, 1821-1875. Lima: Biblioteca Andina.

Macera, P. (1992). Precios del Perú: siglos XVI-XVIII. Lima: Fondo Editorial, Banco Central de Reserva.

Maddison, A. (2007). The World Economy: A Millennial Perspective. París: OECD.

Moreno, F. (1897). Crecimiento, decrecimiento y mortalidad en la ciudad de Lima. Boletín de la Sociedad Geográfica de Lima, 7(7), 145-200.

Özmucur, S. y S. Pamuk (2002). Real Wages and Standards of Living in the Ottoman Empire, 1489-1914. Journal of Economic History, 62(2), 293-321. https://doi.org/10.1017/ S0022050702000517

Peloso, V. (1985). Succulence and Sustenance: Region, Class, and Diet in Nineteenth-Century Peru. En J. C. Super y T. C. Wright (eds.), Food, Politics, and Society in Latin America (pp. 46-64). Lincoln: University of Nebraska Press.

Ponce Vega, L. (1993). Compendio histórico del Perú. Lima: Milla Batres.

Quiroz, A. (1993). Consecuencias económicas y financieras del proceso de la independencia en el Perú, 1800-1850. En L. Prados de la Escosura y S. Amaral (eds.), La independencia americana: consecuencias económicas (pp. 124-146). Madrid: Alianza Editorial.

Romano, R. (1963). Movimiento de los precios y desarrollo económico: El caso de Sudamérica en el siglo XVIII. Desarrollo Económico, 3, 31-43. https://doi.org/10.2307/3465949

Romano, R. (1992). Una polémica sobre la historia de precios en el Buenos Aires virreinal. Boletín del Instituto de Historia Argentina y Americana "Dr. E. Ravignani», 6, 149-162.

Ruiz Zevallos, A. (2001). La multitud, las subsistencias y el trabajo: Lima de 1890 a 1920. Lima: Fondo Editorial de la Pontificia Universidad Católica del Perú.

Seminario de Marzi, L. B. (2011). «Las Cuentas Nacionales del Perú, 1700-2010». Documento de discusión. Universidad del Pacífico DD/12/11.

Smith, A. (1776). Inquiry into the Nature and Causes of the Wealth of Nations. Londres: Methuen \& Co. Ltd. https://doi.org/10.1093/oseo/instance.00043218

Sociedad Geográfica de Lima (1897). Boletín de la Sociedad Geográfica de Lima, 7(7). Lima: Imprenta y Librería San Pedro.

Tantaleán Arbulú, J. (1983). Politica económico-financiera y la formación del Estado: siglo XIX. Lima: CEDEP.

Tantaleán Arbulú, J. (2001). Poder y servidumbre: ensayos de historia, economía y política. Lima: Kavia Cobaya.

Thorp, R. y G. Bertram (1978). Peru 1890-1977, Growth and Policy in an Open Economy. Nueva York: Columbia University Press. https://doi.org/10.1007/978-1-349-03870-1

Twrdek, L. y K. Manzel (2010). The Seed of Abundance and Misery Peruvian Living Standards from the Early Republican Period to the End of the Guano Era (1820-1880). Economics \& Human Biology, 8(2), 145-152. https://doi.org/10.1016/j.ehb.2010.05.012

Vizcarra, C. (2009). Guano, Credible Commitments and Sovereign Debt Repayment in Nineteenth-Century Peru. Journal of Economic History, 69(2), 358-387. https://doi. org/10.1017/S0022050709000813

Wiener, C. (1880). Perou et Bolivie. Recit de voyage suivi d'etudes archeologiques et ethnographiques et de notes sur l'ecriture et les langues des populations indienne. París: Hachette.

Williamson, J. W. (1999). Real Wages, Inequality, and Globalization in Latin America before 1940. Revista de Historia Económica, 17, 101-142. https://doi.org/10.1017/ S0212610900002287

Yepes, E. (1992). La modernización en el Perú del siglo XX: ilusión y realidad. Lima: Mosca Azul. 
148 Economía Vol. XXXIX, Nº 78, 2016 / ISSN 0254-4415

Zegarra, L. F. (2011). Línea de pobreza y salarios, 1913-1925. Una primera aproximación. Economía, 34(67), 39-56. 